\title{
A long term, non-tumorigenic rat hepatocyte cell line and its malignant counterpart, as tools to study hepatocarcinogenesis
}

\author{
Maria Maddalena Angioni ${ }^{1, *}$, Kevin Bellofatto ${ }^{2, *}$, Simone Merlin ${ }^{2}$, Silvia Menegon ${ }^{3}$, \\ Andrea Perra ${ }^{1}$, Annalisa Petrelli ${ }^{3}$, Pia Sulas ${ }^{1}$, Silvia Giordano ${ }^{3}$, Amedeo Columbano ${ }^{1}$, \\ Antonia Follenzi² \\ ${ }^{1}$ Department of Biomedical Sciences, University of Cagliari, 09124 Cagliari, Italy \\ ${ }^{2}$ Department of Health Sciences, University of Piemonte Orientale, 28100 Novara, Italy \\ ${ }^{3}$ Department of Oncology, University of Torino School of Medicine, Candiolo Cancer Institute-FPO, IRCCS, 10060 Candiolo, \\ Italy \\ *These authors have contributed equally to this work \\ Correspondence to: Antonia Follenzi, email: antonia.follenzi@med.uniupo.it \\ Amedeo Columbano, email: columbano@unica.it \\ Silvia Giordano, email: silvia.giordano@unito.it \\ Keywords: resistant hepatocyte, CD90.1, CD24, HCC cell lines, immortalized non-tumorigenic cells \\ Received: March 03, $2016 \quad$ Accepted: January 03, $2017 \quad$ Published: February 01, 2017
}

\section{ABSTRACT}

Hepatocellular carcinoma (HCC) is the fifth most common cancer worldwide and the second cause of cancer-related death. Search for genes/proteins whose expression can discriminate between normal and neoplastic liver is fundamental for diagnostic, prognostic and therapeutic purposes. Currently, the most used in vitro hepatocyte models to study molecular alterations underlying transformation include primary hepatocytes and transformed cell lines. However, each of these models presents limitations. Here we describe the isolation and characterization of two rat hepatocyte cell lines as tools to study liver carcinogenesis. Long-term stable cell lines were obtained from a HCC-bearing rat exposed to the Resistant-Hepatocyte protocol (RH cells) and from a rat subjected to the same model in the absence of carcinogenic treatment, thus not developing HCCs (RNT cells). The presence of several markers identified the hepatocytic origin of both cell lines and confirmed their purity. Although morphologically similar to normal primary hepatocytes, RNT cells were able to survive and grow in monolayer culture for months and were not tumorigenic in vivo. On the contrary, RH cells displayed tumor-initiating cell markers, formed numerous colonies in soft agar and spheroids when grown in 3D and were highly tumorigenic and metastatic after injection into syngeneic rats and immunocompromised mice. Moreover, RNT gene expression profile was similar to normal liver, while that of RH resembled HCC. In conclusion, the two cell lines here described represent a useful tool to investigate the molecular changes underlying hepatocyte transformation and to experimentally demonstrate their role in HCC development.

\section{INTRODUCTION}

Primary cultures of normal hepatocytes are widely used to study the biochemical/molecular events involved in cell death, proliferation and differentiation $[1,2]$. However, several disadvantages limit their use: 1) high inter-individual variability due to differences of the liver of origin (age, gender, healthy/pathological status, xenobiotic treatment);2) the ability to retain only for a short period most of their features, such as their proliferative capacity following specific growth factor stimulation or expression of drug/xenobiotic-metabolizing enzymes [3]. Thus, to improve the maintenance of hepatocyte function and the longevity of the cultures, several alternatives have been developed, but still several problems need to be overcome.

Some conditions were identified to improve in vitro culture, including continuous medium and oxygen supply, and metabolite removal $[4,5]$. In addition, various hollow 
fiber bioreactor systems were developed using hepatocytes of several species [6]. In these systems, cells attach to the surface of fibers or membranes and reorganize themselves into three-dimensional structures that may result in a hepatocyte microenvironment closely resembling the physiological one. Unfortunately, the described cell culture systems are not yet standardized and cannot be easily transferred to other laboratories.

To overcome limitations that negatively regulate human hepatocyte viability and functionality, isolated rodent hepatocytes have been increasingly used as a tool to identify pharmacological and toxicological responses to drugs. Primary rat hepatocytes represent a useful experimental model as their isolation is a relatively easy procedure, guaranteeing a good success rate and an adequate degree of reproducibility. In addition, this procedure provides a large number of cells from a single rat liver. Nevertheless, their use cannot be exploited for studying the biochemical/molecular events leading to cell transformation, as primary hepatocytes survive in culture no longer than 1 week. Even though long-lasting HCC cell lines are useful for drug screening and/or molecular manipulation of gene expression, a major limit in their use is the lack of a normal counterpart for reference.

In the present study, taking advantage of the Resistant Hepatocyte model of rat hepatocarcinogenesis (R-H) [7], we generated and characterized a long-term, non-tumorigenic hepatocyte cell line (RNT), and the corresponding fully transformed cell line (RH). These matched cell lines represent a valuable model to study hepatocarcinogenesis, through genetic engineering aimed at reproducing the multistep process of liver cancer development.

\section{RESULTS}

\section{Isolation and characterization of RNT and RH cell lines}

The R-H model consists of a single injection of DENA followed by a brief exposure to a promoting environment (2-AAF + PH). HCCs arise 10-14 months after DENA treatment (the protocol scheme is shown in Supplementary Figure 1). Control rats exposed to 2-AAF $+\mathrm{PH}$ in the absence of DENA, do not develop tumors. RH and RNT cells were obtained from a rat exposed to the full R-H protocol and from a rat not exposed to DENA, respectively. Briefly, cells were isolated from liver rats through collagenase perfusion by portal vein and maintained in culture. Both cell lines were vital after more than 50 passages in conventional 2D culture dishes, and did not change their morphology and behavior. Therefore, they can be defined as "spontaneously immortalized" cells.

RNT cells exhibit a clear hepatocyte morphology, as they show a typical polygonal architecture and big rounded nuclei; these cells are serum-dependent and show contact inhibition when growing in monolayer (Figure 1A, $1 \mathrm{C}, 1 \mathrm{E})$. On the opposite, a more elongated morphology (fibroblast-like) characterizes RH cells (Figure 1B, 1D), that are able to proliferate under suboptimal culture conditions (low serum, Figure 1E), losing cell-cell contact inhibition and continuing to divide and forming multilayered foci.

Next, we further characterized RNT and RH cells for the expression of hepatocyte and non-hepatocyte markers. Both cell lines were positive for glycogen (as shown by PAS staining), a classical marker of hepatocyte function (Figure 2A). Immunofluorescence and flow cytometry analysis showed that both cell types were also positive for canonical hepatocyte cell markers, such as albumin (Alb, >90\%) and cytokeratin-18 (KRT18, $>95 \%$ ) (Figure 2A, 2B), Moreover, immunofluorescence for transthyretin (TTR), hepatocyte nuclear factor 4-alpha (HNF4A) and transferrin further confirmed the hepatocytic nature of the cells (Figure 3A-3C and Supplementary Figure 2). Performing the analysis for non-hepatocyte markers, we found that only the RH cell line displayed positivity for cytokeratin-19 (KRT19), a typical marker of bile ductular cells and of the so-called oval cells, emerging in pathological conditions [8, 9], including pre- and neoplastic stages (Figure 2A, 2B) [10, 11]. Interestingly, the intermediate filament vimentin - a marker of mesenchymal origin/feature [12] and involved in epithelial-mesenchimal transition (EMT) - was strongly expressed in RH cells, while it was almost completely absent in RNT cells (Figure 4A).

To rule out the presence of non-parenchymal cells, which could have grown together with hepatocytes, we performed immunofluorescent staining for alpha-smooth muscle actin (SMA) (Figure 4B), a marker of activated hepatic stellate cells [13], and for desmin (Figure 4C), a typical intermediate filament in cardiac, skeletal and smooth muscles [13]. The results showed that neither RH, nor RNT exhibited positivity for these non-hepatocyte markers. Lack of desmin, $\alpha$-SMA and vimentin expression was confirmed by flow cytometry analysis (Figure 4E). Tie-2, the tyrosine kinase receptor for angiopoietin 1 [14, 15], is expressed almost exclusively in endothelial cells, in a fraction of monocytes and hematopoietic stem cells [14, 15]. Immunofluorescent staining for this receptor showed that neither RNT nor RH cells did express it (Figure 4D). Additionally, flow cytometry analysis revealed no expression in either cell line of intracellular and extracellular CD68, a macrophage marker (Figure 4E).

Moreover, to prove the hepatocytic nature of the two cell lines, we transduced them with lentiviral vectors expressing GFP under the transcriptional regulation of either hepatocyte-specific promoter or ubiquitous, endothelial- and myeloid-specific promoters. Since transthyretin (TTR) is a hepatocyte secreted protein, its promoter specifically drives transgene expression in hepatocytes [16]. At Multiplicity of Infection (MOI) 
Phase Contrast
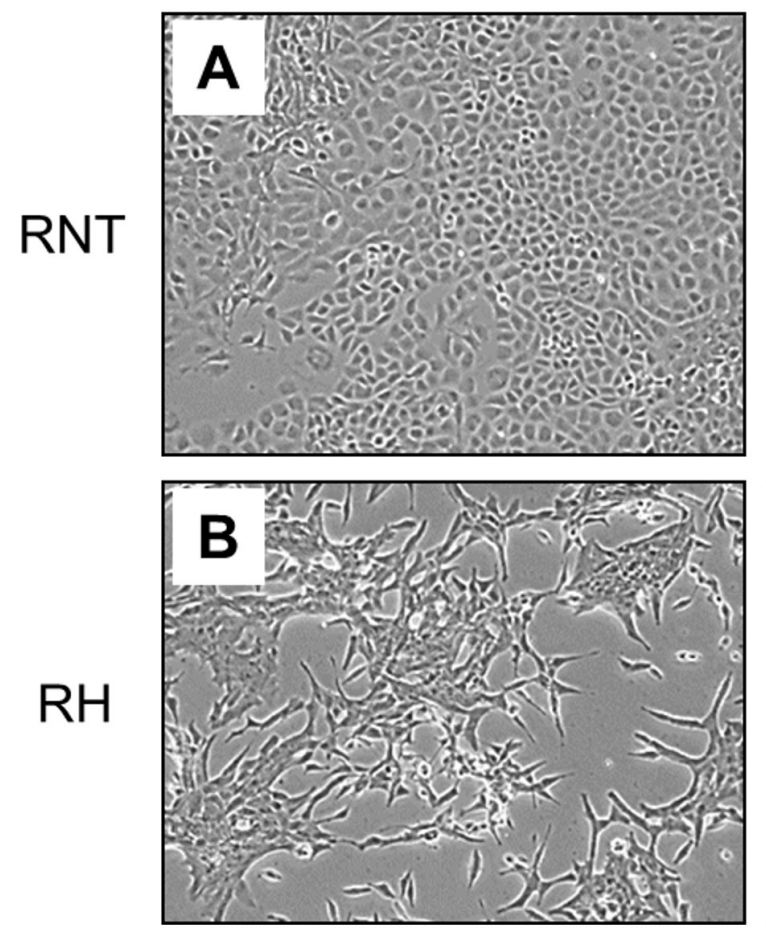

E

\section{$H \& E$}
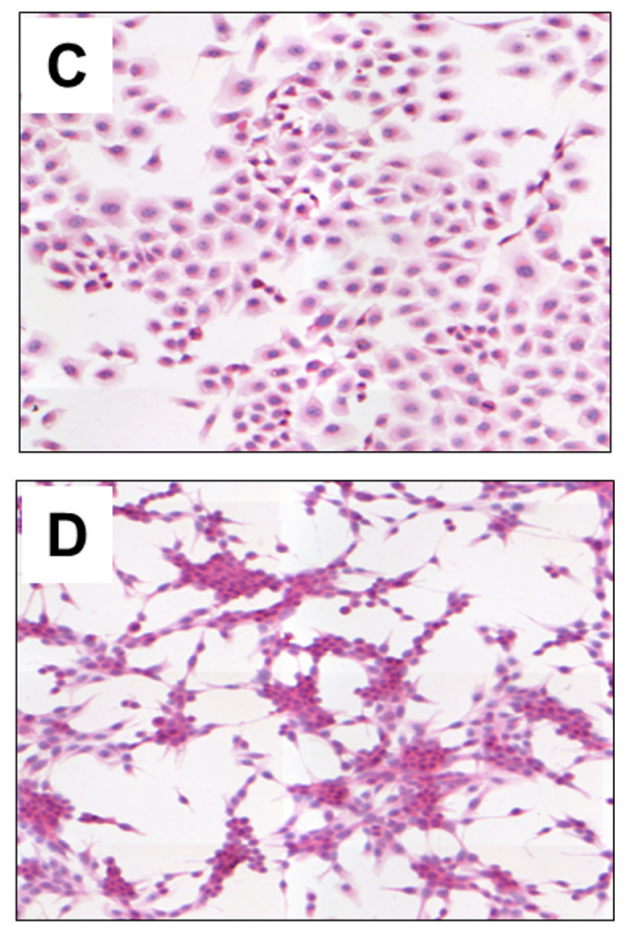

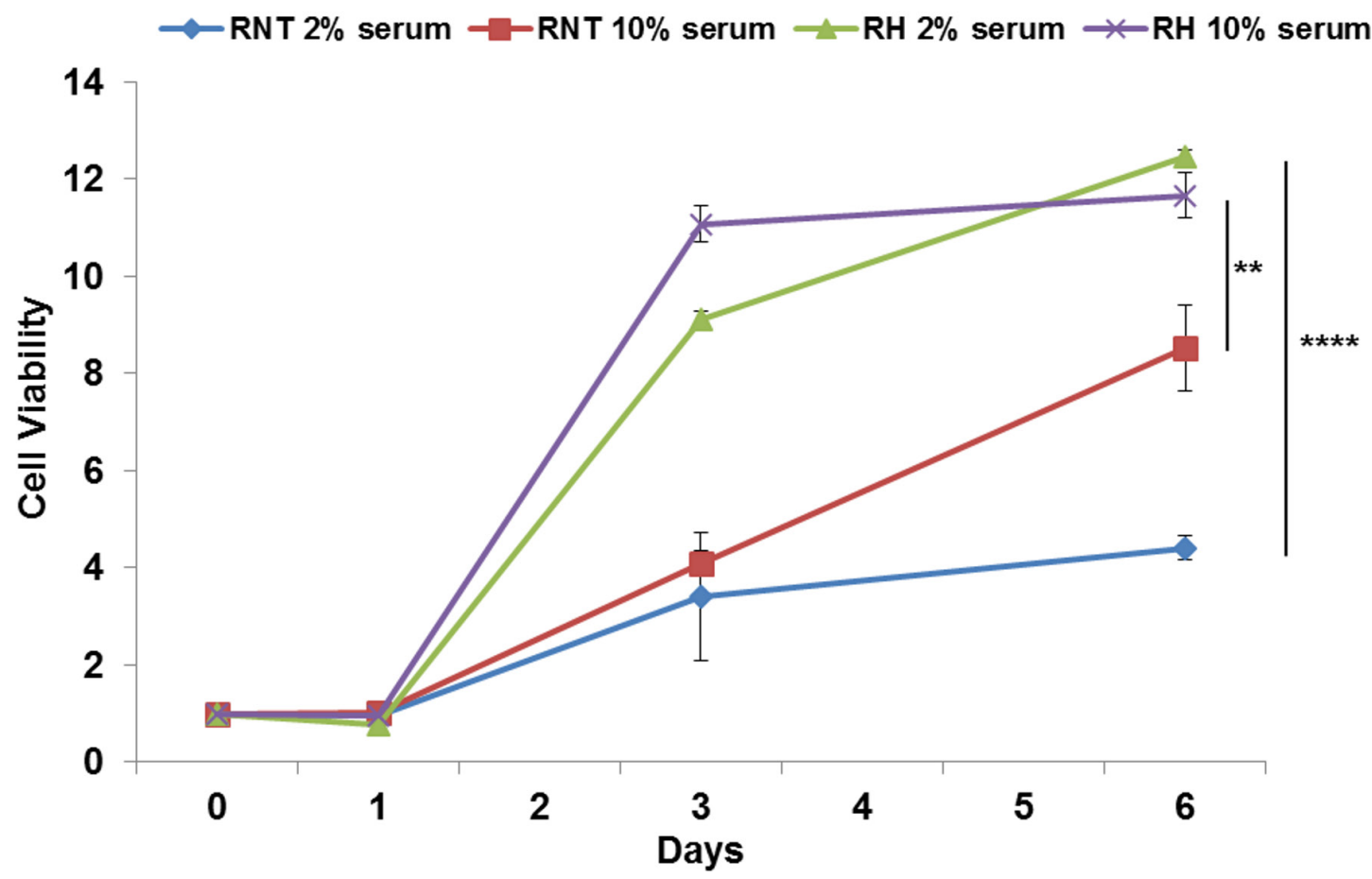

Figure 1: Morphological characterization and growth rate of RNT and RH cells. Phase-contrast microscopy and H\&E staining of cultured RNT A., C. and RH B., D. cells. Magnification 20x. For the experimental procedure followed to obtain the cell lines, see Materials and Methods. E. The growth rate of the two cell lines in adherent conditions, in optimal ( $10 \%$ serum) and suboptimal $(2 \%$ serum) growing conditions, was measured at the indicated times. Cells were fixed and stained with crystal violet; the dye retained by the cells was solubilized in $10 \%$ acetic acid and the Optical Density $(570 \mathrm{~nm})$ was measured. On the $\mathrm{X}$ axis is shown the fold change increase of cell number, compared to time zero. ${ }^{* *} \mathrm{P}<0.01 ; * * * \mathrm{P}<0.0001$. 


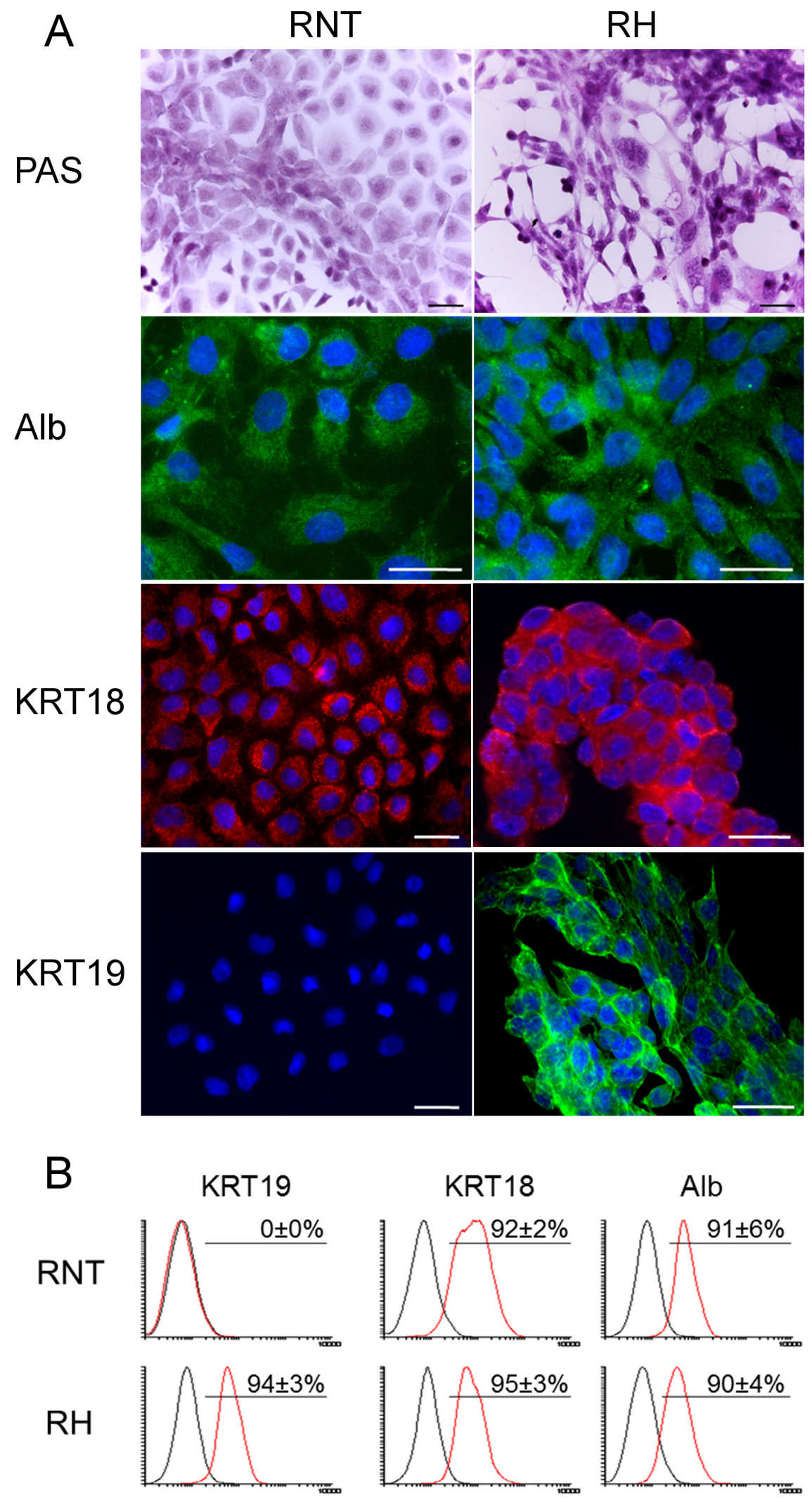

Figure 2: Profiling of typical hepatocyte markers in RNT and RH cells. A. Microphotographs showing positivity for glycogen (PAS staining); A., B. Staining for Albumin (Alb), Cytokeratin 18 (KRT18) and Cytokeratin 19 (KRT19) was assessed by IF (A) and flow cytometry B. analysis in both cell lines. Bars $=25 \mu \mathrm{m}$. 
of 1 , in cultured $\mathrm{RH}$ and RNT cells, the percentage of GFP positive cells was similar to those transduced with a lentiviral vector containing a ubiquitously expressed promoter, the phosphoglycerate kinase 1 (PGK1) promoter (respectively $76 \%$ and $91 \%$ for TTR, 69\% and $83 \%$ for PGK1), confirming the hepatocytic origin of these cells (Figure 5). On the contrary, promoters specific for endothelial and myeloid cells showed low levels of GFP expression (15\% and $26 \%$ for VEC and $11 \%$ and $15 \%$ for CD11b), further demonstrating that the isolated cells were hepatocyte-derived. At the $0.1 \mathrm{MOI}$ the differences were even more pronounced, in line with
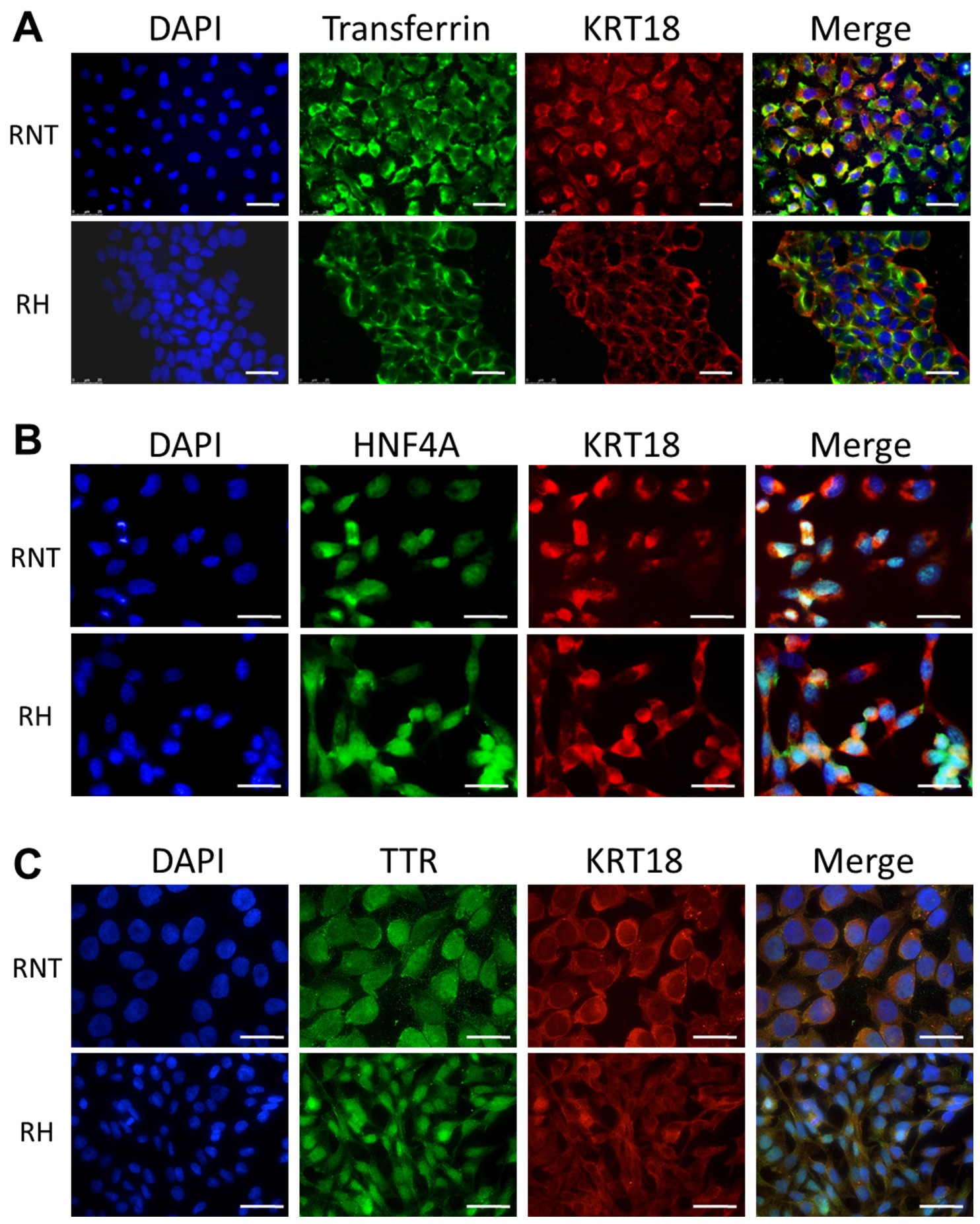

Figure 3: Expression of transferrin, hepatocyte nuclear factor 4 alpha and transthyretin in RNT and RH cells. Coexpression of Transferrin (green) A., hepatocyte nuclear factor 4 alpha (HNF4A) (green) B., transthyretin (TTR) (green) C. and cytokeratin 18 (KRT18; red) in RNT and RH cells. Nuclei were stained with DAPI. Merge of the different stainings is shown in the last column on the right. Bars $=25 \mu \mathrm{m}$. 
the demonstration that these cells are indeed hepatocytes (Supplementary Figure 3A). To validate the specificity of expression of the different described Lentiviruses, we transduced hepatocytic (C1C7), endothelial (MS1) and monocytic (U937) cell lines as controls (Supplementary Figure 3B).

All together, these results demonstrate the hepatocytic nature of cultured RNT and RH cells and rule out a possible contamination by endothelial, macrophages or stellate cells.

\section{RH but not RNT cells express tumor stem cell markers}

Recently, putative liver tumor-initiating cells (T-ICs) have been identified by several cell surface antigens, such as CD90.1, EpCAM and CD24 [17-20]. T-ICs have been suggested to be critical for the maintenance, self-renewal, differentiation, and metastasis of tumors and to significantly impact patients' clinical outcome [21]. Therefore, we investigated by flow cytometry the presence of T-ICs-like cells in both rat cell lines.

As shown in Figure 6A-6D, a small percentage of these two cell lines expressed EpCAM (RNT 5\% and RH 6\%), CD24 (RNT 6\% and RH 10\%) and CD90.1 (RNT $0 \%$ AND RH 1\%). Interestingly, while EpCAM- and CD24- cells co-expressed albumin and cytokeratin 18, $\mathrm{EpCAM}^{+}$and $\mathrm{CD}_{2} 4^{+}$cells were negative for these differentiation markers, further supporting their stem-like nature. Moreover, only RH cells were double positive for CD90.1/CD24, (Figure 6D), as CD90.1 was not detected in the immortalized-non tumorigenic RNT cell line (Figure $6 \mathrm{C})$. These findings show that only RH cells contain tumor stem-like cells, as defined by the double expression of CD90.1 and CD24, in agreement with the results obtained from human samples [21].
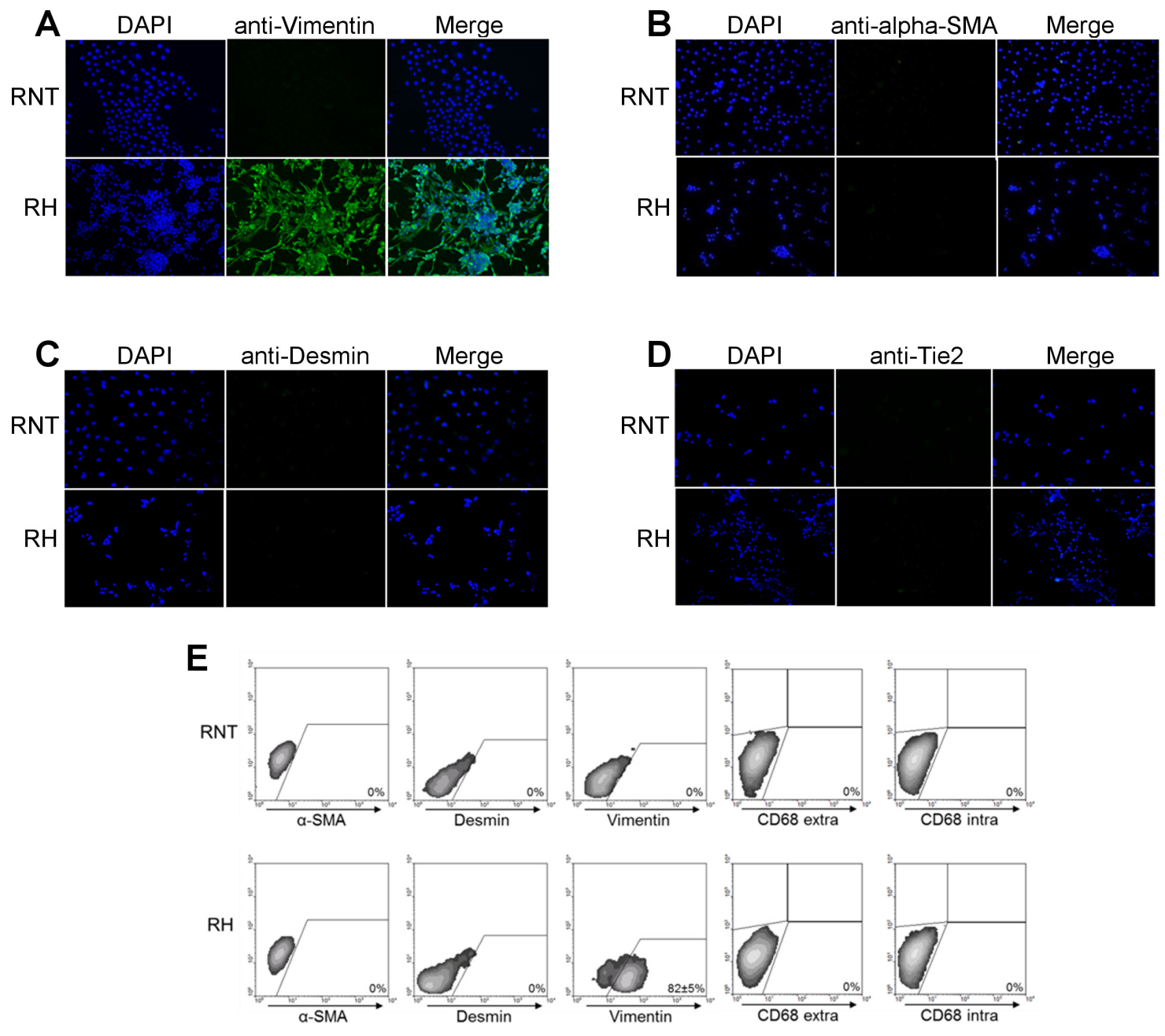

Figure 4: Panel of non-hepatocyte markers in RNT and RH cells. Immunofluorescent staining for Vimentin A., alpha-SMA B., Desmin C. and Tie-2 D. Magnification 20X. E. Flow cytometry analysis of the expression of alpha-SMA, Desmin, Vimentin and the intra/ extracellular macrophage marker CD68. 
To further characterize the two cell lines, we analyzed their growth ability in 3D cultures. We thus generated spheroids and found that RH cells gave rise to more numerous spheroids than RNT cells (Figure 7A). Notably, both cell lines maintained in 3D culture the expression of hepato-specific markers, such as albumin and cytokeratin 18 (Figure 7B, 7D), and of the hepatic precursor marker CD24 (Figure 7C). In the RNT cells CD24 was less represented and the staining for KRT19 (Figure 7B, 7C) was negative confirming the result obtained in the 2D culture of RNT cells (Figure 2A-2B).

To evaluate the gene expression profile of these two cell types we used the Rat Liver Cancer $\mathrm{RT}^{2}$ Profiler PCR Array and found that 44 out of the 84 genes present in the Array were differentially regulated between RH and RNT cells (Threshold $=$ fold change $+/-2$ ) (Supplementary Table 1). As shown in Figure 8, while the Heat Map displayed only minimal differences in each cell type at different culturing passages $(20,40,60)$, the dendrogram clearly separated RH from RNT. Furthermore, by comparing the expression profile of $\mathrm{RH}$ and RNT with normal livers and primary HCCs, we found that RNT clustered together with control livers, while RH were much closer to the HCC sub-cluster (Supplementary Figure 4). Quantitative RTPCR validation performed on randomly selected genes (Birc5, Igfbp1, Myc, Tert, Cnnd1 and Met) confirmed the microarray expression data for all the examined genes (Supplementary Figure 5).

DAVID Functional Analysis of genes altered in RH cells and HCC vs. their respective controls revealed that most of the dysregulated genes are involved in Ubiquitin conjugation, Apoptosis, Phosphoprotein, Glycoprotein and Signal (Supplementary Figure 6A). Pathway analysis also underlined common modifications between $\mathrm{RH}$ cells and HCCs (Pathways in Cancer, MicroRNA in cancer, Hepatitis B, PI3K-AKT-signaling pathway) (Supplementary Figure 6B).

Collectively, these results show that RH and RNT cells not only exhibit a distinct expression profile, but they also maintain features displayed in vivo by transformed and normal hepatocytes, respectively.

\section{RH cells, but not RNT, are endowed with a transformed/tumorigenic potential}

Cell immortalization can be accompanied by transformation. Thus, for both the cell lines, we assessed the transformed/tumorigenic potential typically associated in vitro with the acquisition of anchorage-independent growth ability and in vivo with the capacity to generate tumors when grafted.

When plated in soft agar, RH cells were able to form numerous and large colonies within seven days, while RNT cells did not, even after 3 weeks. (Figure 9A). Moreover, while RH cells were able to form tumor masses in 30 days, when inoculated into the posterior flank of syngeneic rats, RNT cells were completely devoid of tumorigenic ability (Figure 9B, 9C); these tumors showed morphological features of HCC (Figure 9D) and were strongly positive for KRT19 (Figure 9E), thus maintaining the same features of the cells grown in vitro.

As RH cells display EMT features, we wondered if they were able to form metastases. Indeed, one month after grafting, we observed the appearance of lung macro-
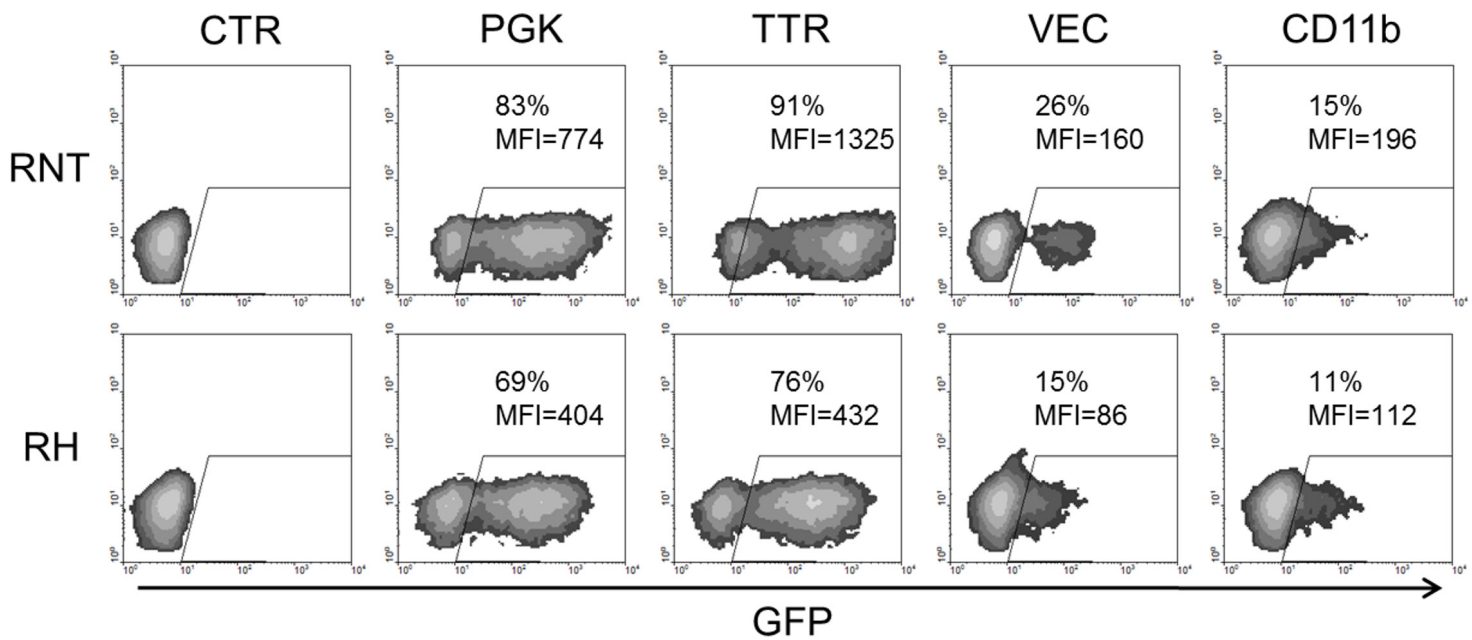

Figure 5: Lentiviral transduction and FACS analysis for promoter-characterization. RNT and RH cells were transduced with four different Lentiviruses (LVs) containing the GFP transgene under the control of ubiquitous (PGK) or cell-specific promoters (TTR, hepatocyte-specific; VEC, endothelial-specific; CD11b, myeloid cells-specific) at MOI 1. GFP expression was evaluated by FACS analysis 72 hours after transduction. GFP expression driven by the hepatocyte-specific TTR promoter in both cell types is comparable to the expression driven by the ubiquitous PGK promoter, while VEC and CD11b promoters were less active in both cell types, confirming the hepatocyte phenotype of these cells. MFI = mean fluorescent intensity. 
metastases (Figure 9F). H\&E and immunohistochemical staining on serial sections of lung metastases showed the maintenance of primary HCC morphology and KRT19 positivity. As expected, RNT cells were unable to originate metastases up to 3 months after grafting (data not shown).

To investigate whether $\mathrm{CD} 24^{+}$stem-like cells are involved in tumor formation, $5 \times 10^{5}$ to $3 \times 10^{6} \mathrm{CD} 24^{+}$ and $\mathrm{CD} 24^{-} \mathrm{RH}$ and RNT cells were injected s.c. into the posterior flank of NOD-SCID yNull mice $(n=5)$, immediately after isolation. While both CD24 positive and negative RNT cells did not give rise to tumors up to 3 months, CD24+ $\mathrm{RH}$ cells generated tumors with a similar size within 14 days in all tested conditions (Figure 9G). As controls we injected $10^{7}$ unselected RH and RNT cells
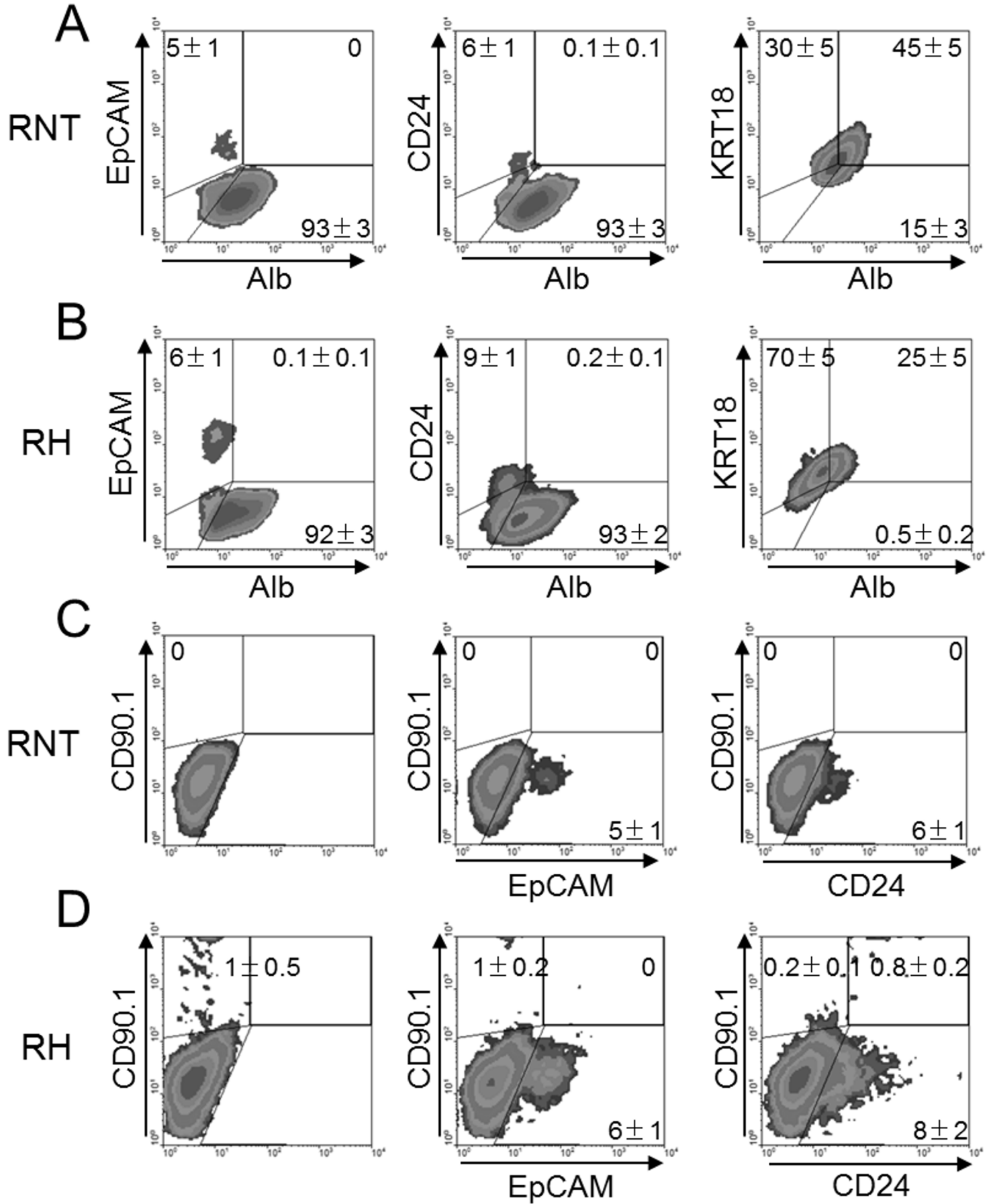

Figure 6: Identification of stem cell-like markers in RNT and RH cells. RNT A and C. and RH B and D. cells were analyzed by flow cytometry for the expression of mature hepatocyte markers (Alb and KRT18), hepatocyte precursor markers (EpCAM and CD24) or the cancer stem cell marker (CD90.1). Numbers indicate the mean of at least 5 different analysis performed \pm SD. 
and only the RH cells formed tumors similar in size to those observed with CD24 positive RH cells. Interestingly, CD24- $\mathrm{RH}$ cells did not give rise to tumors, confirming that tumorigenic cells are in the $\mathrm{CD} 24^{+}$fraction (data not shown). Of note, we found that among the CD24 RH cells, $7 \pm 2 \%$ were also CD $90.1^{+}$, suggesting that this subpopulation could be responsible for the tumorigenic potential of RH cells. In agreement, the CD24 $4^{+} \mathrm{RNT}$ cells did not contain any CD90.1 $1^{+}$cell (Supplementary Figure 7).

\section{RNT/RH cells as a tool to investigate the molecular mechanisms of hepatocarcinogenesis}

The two cell lines we have established represent two different stages of the hepatocarcinogenic process. To provide a proof of concept that they can be used to study the role of candidate molecules in HCC progression, we focused our interest on NRF2. NRF2 is an integrated redox sensitive signaling system that regulates $1 \%-10 \%$ of human genes and is negatively controlled by the ubiquitin ligase KEAP1, which promotes NRF2 proteasomemediated degradation $[22,23]$.

A

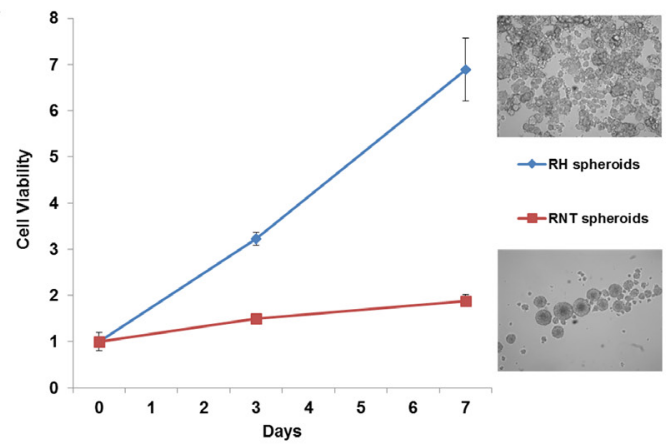

C

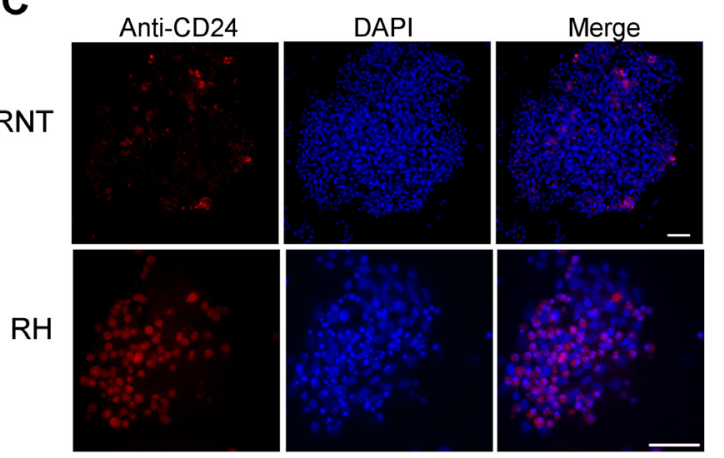

As previously published [24], the NRF2 pathway is already activated in early preneoplastic lesions and along tumor progression. NRF2 silencing in RH cells inhibits their tumorigenic ability, both in vitro and in vivo [25], demonstrating that activation of this pathway is necessary to sustain the malignant phenotype. To investigate if NRF2 activation is "sufficient" to confer transforming ability to RNT cells, we transduced them with a lentiviral vector containing NRF2 cDNA and evaluated their in vitro transforming ability. As shown in Figure 10A, overexpression of NRF2 was not sufficient to confer to the cells the ability to grow in an anchorage-independent manner.

We previously showed that Nrf2/Keapl mutations are present in $59.3 \%$ of HCCs developed in the $\mathrm{R}-\mathrm{H}$ model [25]. Interestingly, while RNT cells are wild type for NRF2, RH cells display an activating mutation (Figure 10B). Therefore, to further stress the system, we transduced RNT cells with constitutively activated forms of this gene, as consequence of activating mutations (Supplementary Figure 8). Transduction of RNT cells with two different NRF2 mutated forms did not confer them in vitro tumorigenic ability. However, RNT cells could be

\section{B}
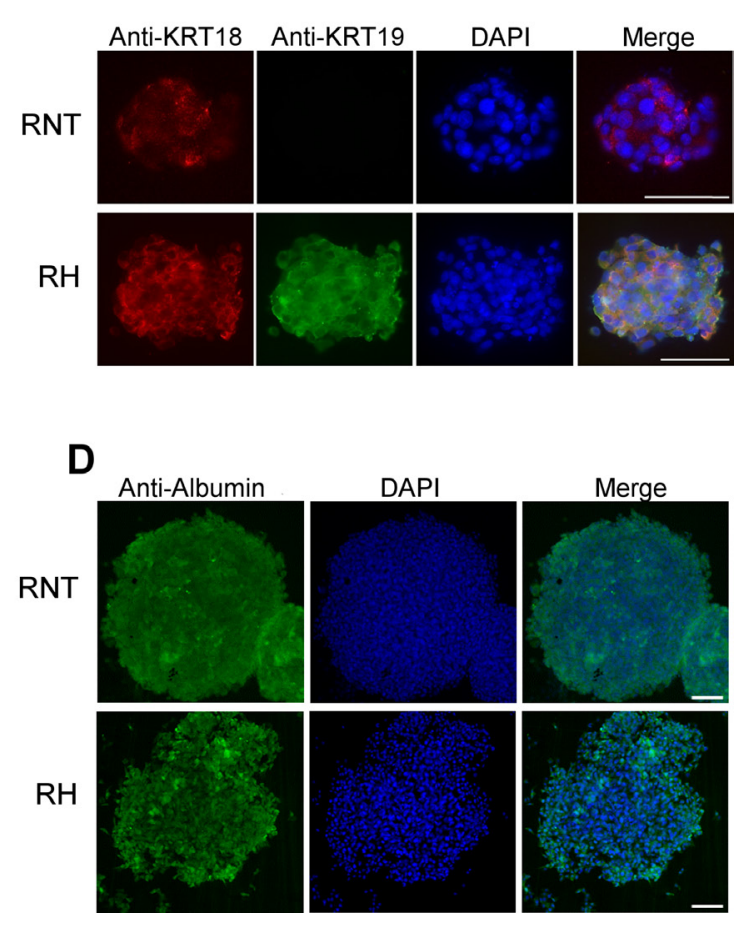

Figure 7: Generation of RNT and RH spheroids. A. The two cell lines were grown in stem medium and low attachment conditions; cell viability was measured at the indicated times. Pictures in the right part of the graph represent RH (upper figure) and RNT spheroids (lower figure) at day 7 (magnification 10X). The X axis shows the fold change increase in cell viability, compared to time zero. Immunofluorescence showing expression of hepatocytes markers KRT18 B. and Alb D. in spheroids of both cell types; on the contrary, KRT19 is present only in RH spheroids (B). A small percentage of RH and RNT spheroids are positive for CD24 C. the number of CD24 ${ }^{+}$ spheroids is higher in RH cells (C). Scale bar $=25 \mu \mathrm{m}$. 
transformed by transduction of a well-known oncogene, such as the active (G12V) KRAS (Figure 10A).

All together, these experiments show that NRF2 activation is necessary to sustain the tumorigenic status but is not sufficient per se to induce it.

\section{DISCUSSION}

In the present paper, we report the in vitro establishment and the functional characterization of two novel rat immortalized hepatocytic cell lines: $\mathrm{RH}$ and RNT. Both cell lines were obtained by perfusion of rat livers exposed to the Resistant-Hepatocyte protocol, in the presence or in the absence of carcinogenic treatment, and could be maintained in culture for more than 50 passages, without signs of senescence (data not shown).
Both cell lines display features typical of hepatocytes as they are glycogen-positive, produce albumin and express KRT18, and are not contaminated by other cell types usually present in the liver, such as macrophages, stellate cells, and endothelial cells. However, obvious differences exist between them, as RNT cells display a typical hepatocytic morphology, while RH cells show a fibroblastoid shape, with signs of EMT. EMT is a critical event in the induction of cell motility and invasion, both in physiological conditions - like wound healing or development - and in malignant transformation - when tumor cells acquire invasive/metastatic properties. Indeed, vimentin - an intermediate filament protein characteristically upregulated in cells undergoing EMT $[12,26,27]$ - was only weakly expressed in RNT cells, while it was strongly up-regulated in RH cells, in

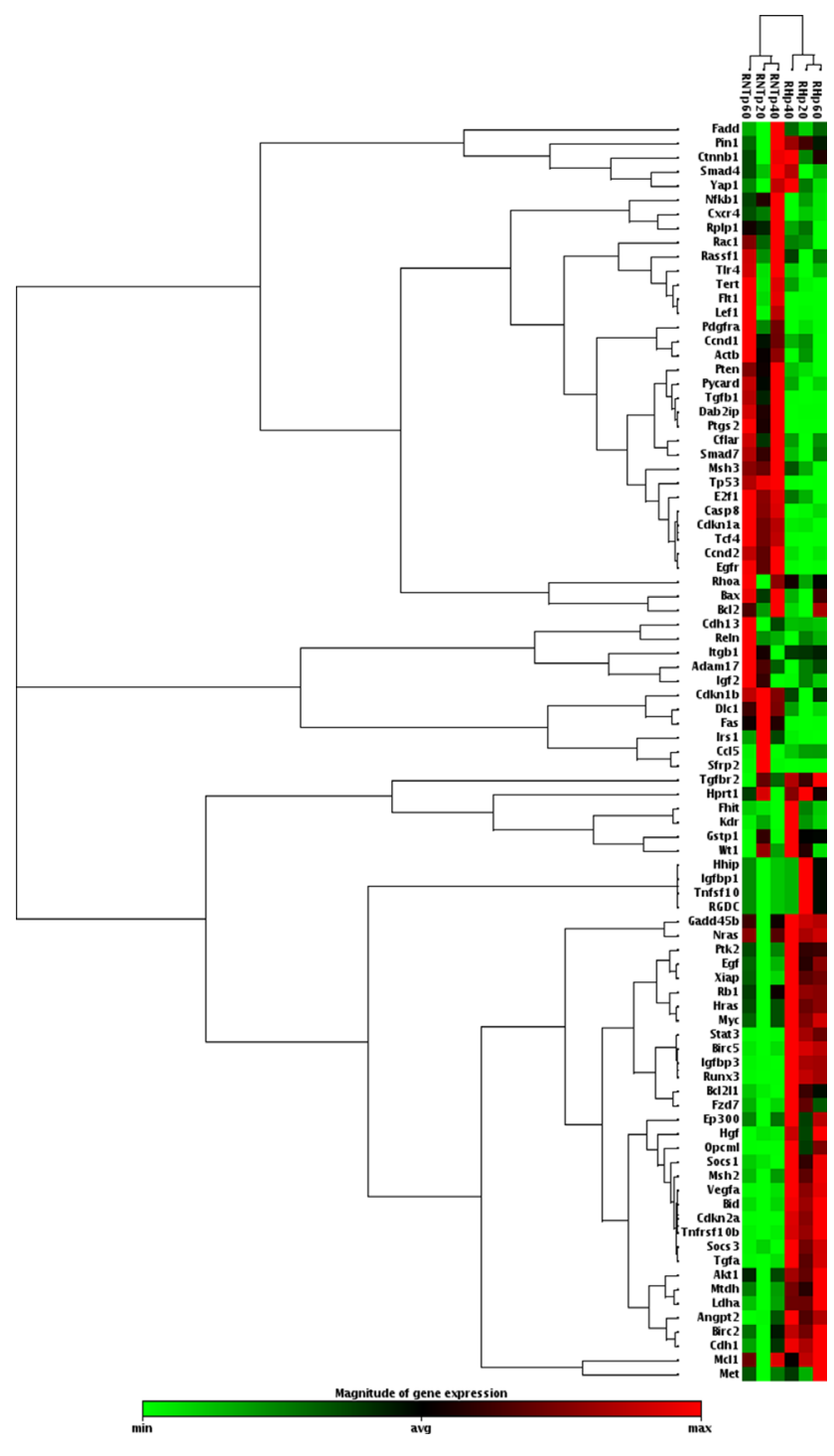

Figure 8: Hierarchical clustering of 84 genes in RNT and RH cells. Each row represents the expression profile of a gene. Only mRNAs whose expression was dysregulated at least by 2-fold were considered. Red and green colors represent higher or lower expression levels of the mRNA (median-centered), respectively. 
agreement with their fibroblastoid shape and increased metastatic ability.

The performed gene expression profiling showed not only that many of the evaluated genes were differentially expressed, but also that RNT cells display a profile similar to normal livers while RH are very similar to HCCs.

Another relevant difference concerns the expression of KRT19 that was observed only in RH tumorigenic cells. In normal liver, hepatocytes express KRT8 and KRT18, whereas biliary epithelial cells express KRT7 and KRT19 [8, 9]. However, the presence of KRT19 hepatocytes has been demonstrated in a subset of human HCCs characterized by the worst prognosis among all HCC subclasses, suggesting that KRT19 is a negative prognostic marker $[11,28]$. Moreover, in the Resistant-
Hepatocyte model, although KRT19+ lesions represent a minority of the total preneoplastic lesions, most HCCs are $\mathrm{KRT}_{19}{ }^{+}$, further suggesting that KRT19 ${ }^{+}$preneoplastic hepatocytes preferentially progress to malignancy [10, 24]. Furthermore, KRT $19^{+}$HCCs show significantly increased EMT features and expression of invasion-related molecules, suggesting that they are endowed with higher invasive ability, compared to KRT19- HCCs [28].

Another important difference between the two cell lines is the presence of tumor stem-like cells only in the $\mathrm{RH}$ cell line. We have investigated three markers that have been associated to T-ICs, namely CD90.1, CD24 and EpCAM [17-20]. The CD90.1 (Thy-1) antigen is expressed in bone-marrow derived stem cells and hepatic stem/progenitor cells (both in adult and fetal

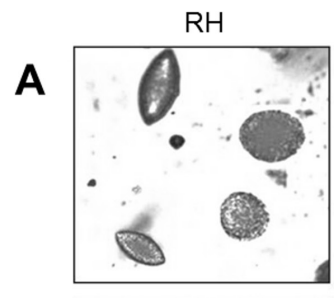

B

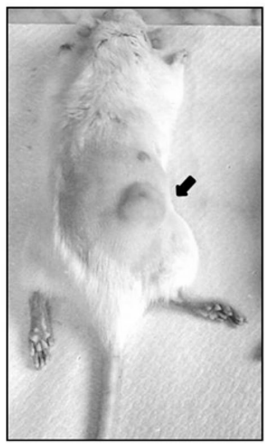

C

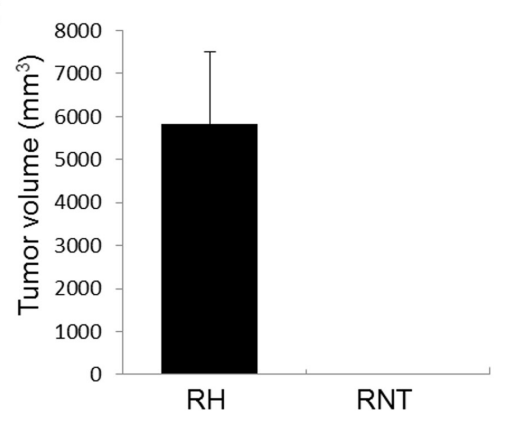

D

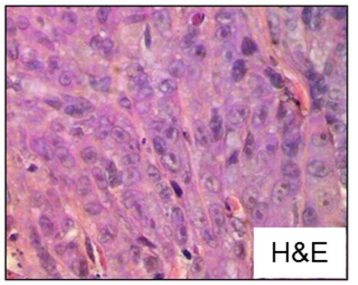

E
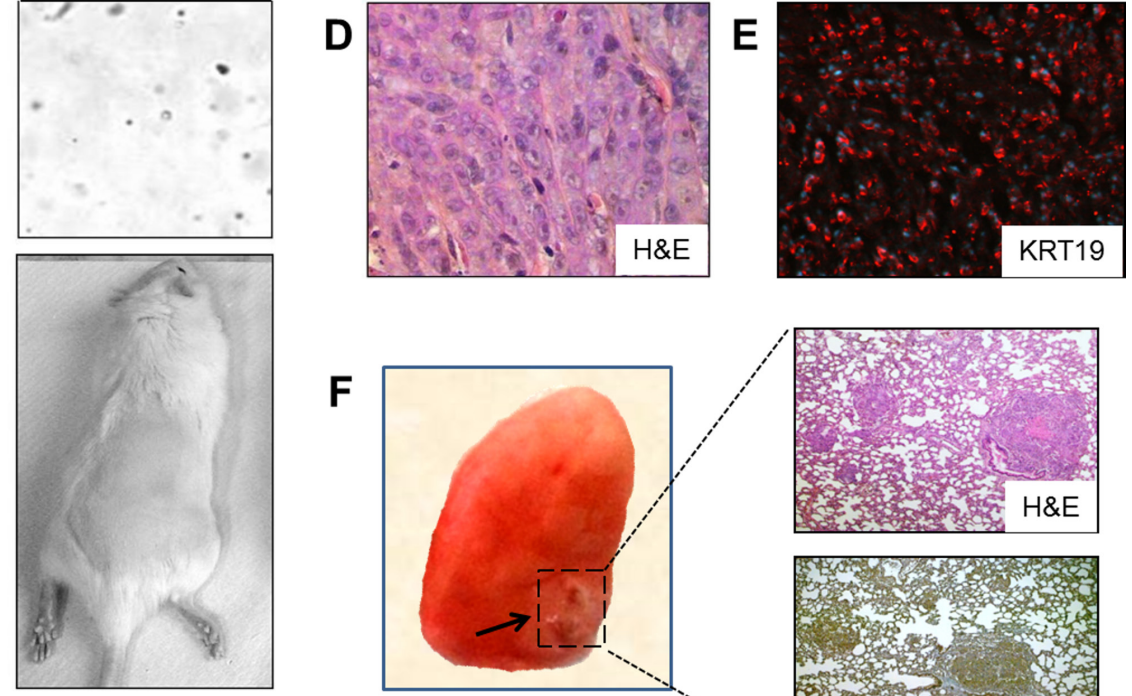

G 2000

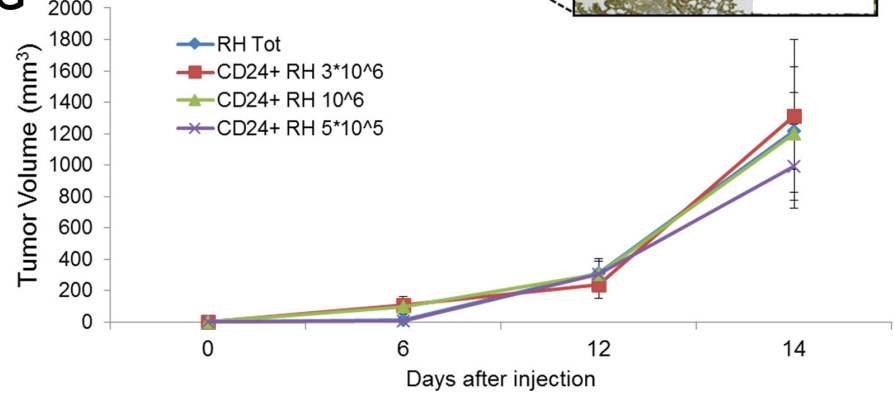

Figure 9: Biological assays and tumorigenesis. A. The ability to grow in anchorage-independent conditions was assessed by soft agar assay. Colonies were photographed after two weeks. B. Representative photographs of syngeneic rats injected with RH (left) or RNT (right) cells. RH and RNT cells were inoculated into the posterior flank of syngeneic rats $\left(1.5^{*} 10^{6}\right.$ cells/injection); C. Graph showing the tumor volume of rats, 19 days after injection with RH or RNT. The results represent the mean \pm SD of 5 animals/group; D. Microphotograph showing H\&E staining of a HCC developed 19 days after injection of RH cells; E. Microphotograph illustrating a strong positivity of KRT19 in the same HCC; F. (Left) Macroscopic photograph of a lung from a rat injected with RH cells and killed 30 days after grafting. A metastasis is shown by the arrow. (Right) Microphotographs of the metastasis shown in F, stained for H\&E (top) and KRT19 (bottom; Magnification 10x); G. Unselected (Tot) and CD24 $4^{+} \mathrm{H}$ cells were inoculated into the posterior flank of NOD-SCID $\gamma \mathrm{Null}$ mice (10 ${ }^{7}$ cells/ injection for unselected RH cells and $5 \times 10^{5}, 1 \times 10^{6}$ and $3 \times 10^{6}$ for $\mathrm{CD} 24^{+} \mathrm{RH}$ cells). The graph shows tumor growth in mice up to 14 days after injection. The results represent the mean $\pm \mathrm{SD}$ of 5 animals/group. 
livers, but not in adult hepatocytes)[29]. In the liver, CD90.1 expression was found preferably in poorly differentiated HCCs and associated with a poor prognosis [30]. Moreover, only CD $90.1^{+}$cells obtained from HCCs displayed tumorigenic and metastatic capacity when injected into immunodeficient mice [31]. CD24, which is overexpressed in various human malignancies [32, 33], was expressed at higher level in RH than in RNT cells. More interestingly, the CD90.1 marker was present only in $\mathrm{RH}$ cells, where it is co-expressed within the CD24+ population. Actually, both markers were reported to be involved in CSC differentiation in HCC [34]. Interestingly, only the $\mathrm{CD} 24^{+} \mathrm{RH}$ population (containing also CD $90.1^{+}$ cells) was endowed with tumorigenic ability, while neither CD24- RH cells nor CD24+ RNT cells (that do not display $\mathrm{CD} 90.1^{+}$), gave rise to tumors after subcutaneous implantation in mice.

A critical difference between the two cell lines is that only RH cells displayed the typical behavior of malignant transformed cells, as in vitro they grow in anchorageindependent manner and do not show contact inhibition, and in vivo are strongly tumorigenic and metastatic. Interestingly,
RNT cells are immortalized but not tumorigenic. Thus, they represent a critical "normal" counterpart of RH transformed cells. As these two cell lines epitomize two steps in the natural history of tumor development, they can therefore be used to study the molecular mechanisms underlying tumor progression. Indeed, we have shown that NRF2 silencing in RH cells reverted their phenotype toward that of RNT cells, demonstrating that activation of the NRF2 pathway is required to maintain the transformed phenotype [25]. However, exogenous expression of NRF2 - or even of activated forms of this gene - did not promote the progression toward a transformed phenotype. On the other hand RNT cells could be transformed by transduction with an oncogenic form of KRAS, thus proving their susceptibility to become tumorigenic. All together, these results suggest that NRF2 constitutive activation is not sufficient to promote the transformation of the immortalized liver cells. The analysis of differentially expressed and mutated genes in RH vs. RNT cells can thus help in the identification of the genes that complement NRF2 in promoting transformation. Exogenous expression/silencing of

\section{A}

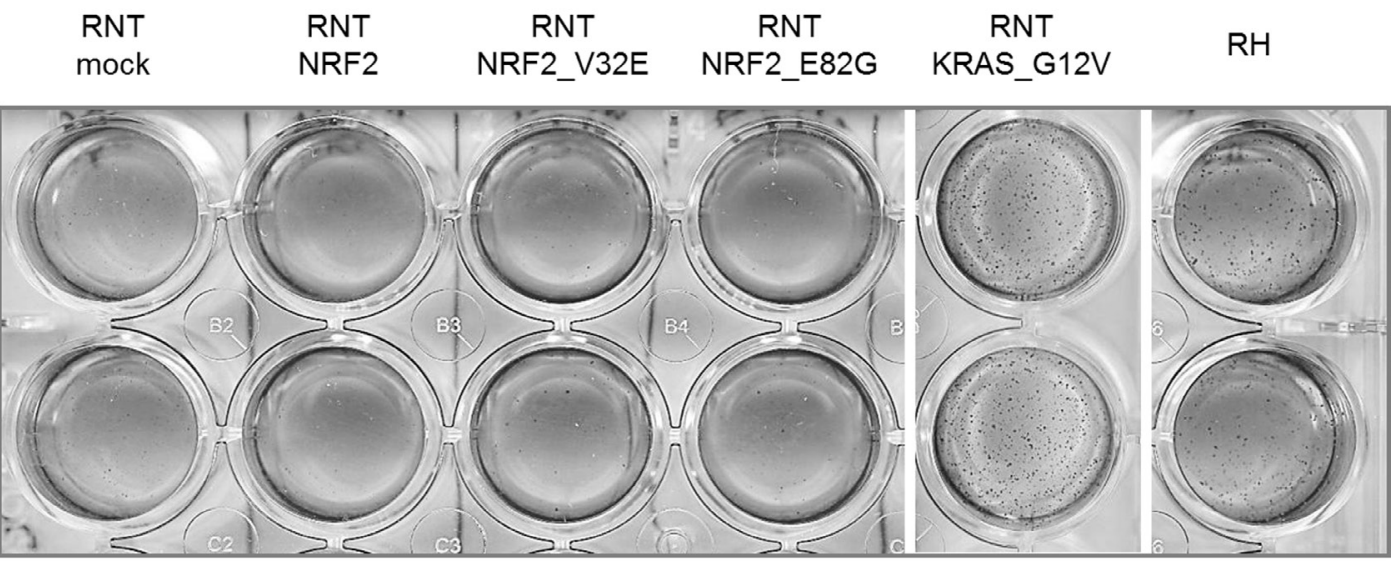

B

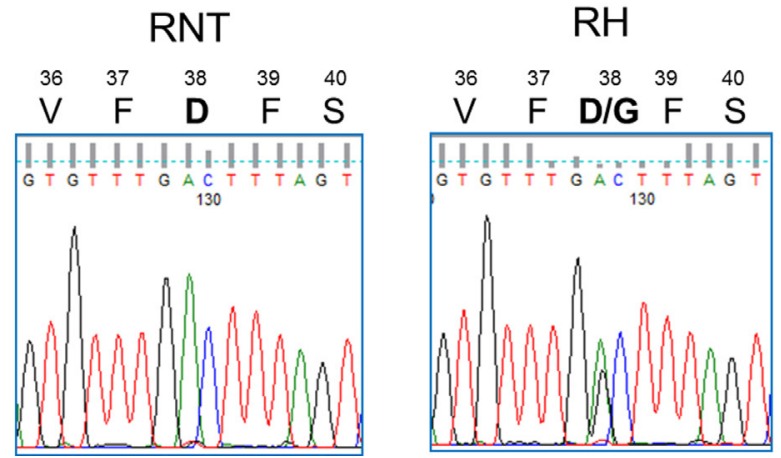

Figure 10: NRF2 transduction is not sufficient to transform RNT cells. A. RNT cells were transduced with the indicated constructs (mock vector, wild type NRF2, NRF2 constructs bearing activating mutations, activated KRAS). The ability to grow in anchorage-independent conditions was assessed by soft agar assay. Colonies were photographed after two weeks. RH cells were used as positive controls for the growth in soft agar. B. Pherograms showing the presence of a NRF2 activating mutation (D38G) in RH but not in RNT cells. 
selected genes will allow to experimentally prove the results obtained in silico.

In conclusion, the two cell lines here described represent a useful tool for investigating the molecular changes underlying hepatocyte transformation and to experimentally demonstrate their role in $\mathrm{HCC}$ development.

\section{MATERIALS AND METHODS}

\section{Animals and treatment}

Guidelines for Care and Use of Laboratory Animals were followed during the investigation. All animal procedures were approved by the Ethical Commission of the University of Cagliari and the Italian Ministry of Health. Male Fischer F-344 rats (100-125 g) purchased from Charles River (Milan, Italy) and NOD.CgPrkdcscidIl2 $\mathrm{rgtm} 1 \mathrm{Wjl} / \mathrm{SzJ}$ mice ( $\gamma \mathrm{Null}$ ) were originally by Jackson Laboratories (Bar Harbor, Maine, USA). Animals were kept on a laboratory diet (Ditta Mucedola, Milan, Italy) and given food and water ad libitum with a 12-hour light/dark daily cycle.

HCC was induced according to the Resistant Hepatocytes (R-H) model [7]. Rats were injected intraperitoneally with the chemical carcinogen diethylnitrosamine (DENA, Sigma, MO) at a dose of 150 $\mathrm{mg} / \mathrm{kg}$ body weight. After a 2 -week recovery, rats were fed a diet containing $0.02 \%$ 2-acetylaminofluorene (2AAF, Sigma, MO) for 1 week followed by a two-thirds partial hepatectomy (2/3 $\mathrm{PH})$, and an additional week of 2-acetylaminofluorene diet. The animals were then returned to the basal diet and euthanized at 14 months (Supplementary Figure 1). Rats exposed to 2-AAF and $2 / 3 \mathrm{PH}$, but in the absence of carcinogen, were used as controls.

\section{Cell isolation and culturing}

RNT (Rat Not Tumorigenic) and RH (Resistant Hepatocytes) cells were obtained from rats treated with 2-AAF + PH (rats with no tumors) or DENA + 2-AAF $+\mathrm{PH}$ (tumor bearing rats), respectively. Livers were perfused at $10 \mathrm{ml} / \mathrm{min}$ via portal vein for 5 minutes with Leffert's buffer (at $37^{\circ} \mathrm{C}$ ) containing $1.9 \mathrm{mg} / \mathrm{ml}$ EGTA, for 2 minutes with buffer lacking EGTA, and for $10-15$ minutes with buffer containing $0.03 \%(\mathrm{w} / \mathrm{v})$ collagenase (Worthington Biochemical Corp.) and $5 \mathrm{mM}$ $\mathrm{CaCl}_{2} .2 \mathrm{H}_{2} \mathrm{O}$, as described [35], with modification for rat liver. The perfusion buffer contained $10 \mathrm{mmol} / \mathrm{l} \mathrm{HEPES}$, $3 \mathrm{mmol} / \mathrm{l} \mathrm{KCl}, 130 \mathrm{mmol} / 1 \mathrm{NaCl}, 1 \mathrm{mmol} / 1 \mathrm{NaH}_{2} \mathrm{PO}_{4}$. $\mathrm{H}_{2} \mathrm{O}$, and $10 \mathrm{mmol} / \mathrm{l} \mathrm{d}$-glucose, $\mathrm{pH}$ 7.4). The livers were dissociated in Leffert's buffer, and cells were passed through Dacron fabric with $80-\mu \mathrm{m}$ pores and centrifuged under $50 \mathrm{~g}$ for 5 minutes to recover hepatocytes. For livers containing tumors, digestion continued in the plastic dish for additional 10-20 min in the presence of collagenase: after incubation, tumor masses present in the remaining parenchyma were mechanically disrupted. Cells were recovered and washed several times in serum-free medium; then hepatocytes were maintained in petri dishes coated with rat tail collagen $0,2 \%$, in 10\% FBS DMEM.

Murine peritoneal macrophages were collected by intraperitoneal injection of RPMI-1640 and maintained in 5\% FBS RPMI-1640.

Cultured RNT and RH cells were maintained in 10\% FBS RPMI with P/S (100U/ml Penicillin, 100mg/l Streptamicin), and L-Glutamine (2mM). C1C7 (murine HCC cell line), MS1 (murine endothelial cell line), U937 (human macrophage cell line) and HTC (rat hepatoma cell line) were maintained in 10\% FBS DMEM.

\section{RNT and RH spheroids}

To obtain spheroids from RNT and RH cells, cells were seeded in low-attachment $24-w e l l$ plates $\left(10^{4}\right.$ cells/ well) in stem medium conditions (0\% FBS DMEM-F12 medium, supplemented with EGF, bFGF, insulin and B-27 supplement). After the formation of spheroids, they were seeded in low-attachment 96-well plates and cell viability was evaluated at days 0,3 and 7 after seeding, using CellTiterGlo assay (Promega).

\section{Periodic acid-schiff (PAS) stain for glycogen}

Culture dishes containing cells were fixed in ethanol - acetic acid (99:1) for 10 minutes at $4^{\circ} \mathrm{C}$, incubated with Schiff reagent for 5 minutes and washed twice with periodic acid (Carlo Erba).

\section{Immunofluorescence (IF) analysis}

Cells were seeded on collagen-coated coverslips for $48 \mathrm{~h}$, subsequently rinsed with PBS and subjected to immunofluorescence. RNT and RH spheroids were prepared by cyto-spin at $1000 \mathrm{rpm}$ for $5 \mathrm{~min}$. Cells were fixed with $4 \%$ paraformaldehyde (Sigma Aldrich) or with methanol (Sigma-Aldrich) at room temperature and permeabilized with PBS containing $0.1 \%$ Triton X-100 (Sigma-Aldrich). After blocking with 5\% goat serum (Sigma Aldrich), cells were subjected to immunofluorescence staining with primary antibodies diluted in PBS containing 1\% BSA, $0.1 \%$ Triton X-100 and 2\% goat serum, as listed in Supplementary Table 2.

Cells were finally incubated with either secondary anti-mouse, anti-rabbit AlexaFluor 488-conjugated or AlexaFluor 546-conjugated antibodies (dilution 1:500, Invitrogen, Carlsbad, CA) for $1 \mathrm{~h}$ in PBS containing $1 \%$ BSA and $0.1 \%$ Triton X-100. Nuclei were stained with DAPI (Sigma Aldrich). As a control, staining of RNT and $\mathrm{RH}$ was performed with the secondary antibody alone 
(Supplementary Figure 9). Cells were examined by fluorescence microscopy (Olympus America Inc, Center Valley, PA). Images were acquired as sets of colorimages and prepared using Photopaint and Photoshop software.

\section{Cytofluorimetric analysis}

To analyze extracellular markers, cells were re-suspended in staining buffer (PBS, 1\% FBS, 0.1\% $\mathrm{NaN}_{3}$ ) followed by incubation with specific antibodies for 30 minutes on ice. For intracellular markers, cells were re-suspended in staining buffer containing $1 \%$ paraformaldehyde for 5 minutes, incubated with Perm wash buffer (BD Biosciences, San Diego, CA) for 5 minutes, followed by incubation with primary antibody in Perm/Wash buffer for 30 minutes on ice. Finally, cells were washed twice in Perm/Wash buffer (BD Biosciences) and re-suspended in staining buffer. Specific antibodies used are listed in Supplementary Table 3.

\section{Lentiviral transduction}

Four different lentiviral vectors expressing the green fluorescence protein (GFP) under the control of PGK (Phosphoglycerate kinase, ubiquitous), TTR (Transthyretin, hepatocyte specific), VEC (VascularEndothelial Cadherin, endothelial specific) and CD11b (Integrin alpha M, ITGAM, myeloid cells specific) promoters were used to transduce RH and RNT cells. As controls we used the following cell lines: C1C7 murine hepatocytes, MS1 murine endothelial cells, U937 human monocytes. Cells were transduced with a multiplicity of infection (MOI) of 1 and 0.1. Expression level and stability of the GFP expression was evaluated by flow cytometry $72 \mathrm{~h}$ after transduction.

RNT cells were stably transduced with an empty lentiviral vector (mock), with an NRF2 lentiviral construct (217EX-T3128-Lv157; GeneCopoeia, Rockville, MD), with the mutant forms of NRF2 (V32E and E82G), obtained using the QuikChange II XL Site-Directed Mutagenesis Kit (Agilent Technologies), and with a lentiviral construct expressing the activated form of KRAS G12V.

\section{$\mathrm{CD}^{+} 4^{+}$cells isolation}

For $\mathrm{CD}_{24^{+}}$cells isolation, $\mathrm{RH}$ and RNT cells were first incubated for $20 \mathrm{~min}$ at $4{ }^{\circ} \mathrm{C}$ with anti-rat CD24 PEconjugated antibody (Miltenyi Biotec) followed by a second incubation with anti-PE Microbeads (Miltenyi Biotec) for $20 \mathrm{~min}$ at $4^{\circ} \mathrm{C}$ and finally immunomagnetically separated using magnetic columns (Miltenyi Biotec). Cell purity was verified by flow cytometry. Freshly isolated cells were then counted and immediately injected s.c. into yNull mice.

\section{Cell growth}

RNT and RH cells were seeded in 96-well plates (4000 cells/well) at two different concentrations of serum ( $2 \%$ and $10 \%$ ). Cells were fixed in $11 \%$ glutaraldehyde and stained with crystal violet at days 1, 3 and 6 after seeding. The dye retained by the cells was then solubilized in $10 \%$ acetic acid and the Optical Density (570nm) was measured using a Multilabel Reader (PerkinElmer, Waltham, MT, USA).

For evaluation of anchorage-independent growth, 3000 cells/well were seeded in 10\% FBS RPMI 0.5\% soft agar and maintained in the presence of medium for 15 days. Grown colonies were visualized by staining with crystal violet and pictures acquired as sets of $\mathrm{b} / \mathrm{w}$ images by microscope.

\section{RH and RNT expression profile by qRT-PCR}

Total RNA from cultured RH and RNT at different culturing passages and from normal rat livers and HCCs was first extracted by using TRIzol® reagent (Invitrogen) and further purified using the RNeasy Micro Kit (Qiagen). cDNA was obtained from $1 \mu \mathrm{g}$ of RNA using the RT ${ }^{2}$ First Strand Kit (Qiagen). Gene expression profile of RH, RNT, normal livers and tumors was analyzed by real-time qPCR using the Rat Liver Cancer RT $^{2}$ Profiler ${ }^{\mathrm{TM}}$ PCR Array (Qiagen), that evaluates 84 genes. Analysis was performed using the Web-based PCR Array Data Analysis Software available at SAB website (www.SABiosciences.com/ pcrdataanalysis.php). B2m was used as housekeeping gene. Only mRNAs whose expression was dysregulated by at least 2-fold compared to their controls were considered modified.

\section{QRT-PCR validation}

Analysis of Birc5, Igfbp1, Myc, Tert, Cnnd1 and Met expression was performed using specific TaqMan probes (Applied Biosystems); GAPDH was used as endogenous control. The results are the mean of three different samples/group.

\section{Pathway and functional analysis by means of the DAVID bioinformatics resources software}

The functional enrichment analysis of the differentially expressed genes was performed with the Database for Annotation, Visualization and Integrated Discovery (DAVID), including gene ontology (GO) function analysis and Kyoto Encyclopedia of Genes and Genomes (KEGG) pathway analysis. Analysis of pathways and functions was based on the number of genes significantly dysregulated (fold difference cutoff +2.0 ). In KEGG pathway analysis, enriched pathways were identified according to the hypergeometric distribution with a P-value $<0.01$. 


\section{In vivo experiments}

The rat in vivo experiments were performed by inoculating s.c. $1.5 \times 10^{6}$ cells (suspended in sterile PBS/ Matrigel ratio 1:1) into the posterior flank of F344 male rats. For experiments performed in mice, $10^{7}$ unselected $\mathrm{RH}$ or RNT cells or $5 \times 10^{5}-3 \times 10^{6} \mathrm{CD} 24^{+}$or $\mathrm{CD} 24^{-} \mathrm{RH}$ or RNT cells were inoculated in the same manner in $\gamma$ Null mice. Tumor masses were measured with a caliper. Tumors were then resected and analyzed by H\&E stain and IF. Lungs were surgically removed to histologically verify the presence of metastases.

\section{Abbreviations}

R-H: resistant-hepatocyte model; DENA: diethylnitrosamine; AAF: acetylaminofluorene; $\mathrm{PH}$ : partial hepatectomy; RH cells: rat hepatocarcinoma cells; RNT cells: rat non-tumorigenic cells; HCC: hepatocellular carcinoma; KRT19: cytokeratin 19; TTR: transthyretin; PGK1: phosphoglycerate kinase 1; GFP: green fluorescent protein; HNF4A: hepatocyte nuclear factor 4-alpha; EMT: epithelial-mesenchimal transition; NRF2:nuclear factor (erythroid-derived 2)-like 2; VEC: Vascular-Endothelial Cadherin, endothelial specific); CD11b: Integrin alpha M, ITGAM, myeloid cells specific.

\section{CONFLICTS OF INTEREST}

No conflicts of interest to declare.

\section{GRANT SUPPORT}

This work was supported by grants from Associazione Italiana Ricerca sul Cancro (Grants IG15279 to AC, IG-15464 to SG, IG-13166 to AF), Ministero Università e Ricerca Scientifica, R.A.S. 2012 to $\mathrm{AC}$ and Fondazione Banco di Sardegna to AC, and AP. ERC start up grant n. 261176 to AF.

\section{Authors' contributions}

MMA, AF: isolation and maintenance of $\mathrm{RH}$ and RNT cells; MMA, KB, SMer: Immunohistochemistry and Immunofluorescence; KB, SMer: tumor grafting of RH and RNT cells in immunocompromised mice, lentiviral transduction, flow cytometry analysis and RNA extraction for superarray preparation and analysis; AP: tumor grafting in rats; SMen, APet: growth curve, soft agar assays and spheroids generation; PS: acquisition and analysis of qRT-PCR data; AF, AC, SG: study concept and design, analysis and interpretation of data, drafting of the manuscript. All Authors discussed the results and commented the manuscript.

\section{REFERENCES}

1. Lake BG, Price RJ, Giddings AM, Walters DG. In vitro assays for induction of drug metabolism. Methods in molecular biology. 2009; 481:47-58.

2. Swift B, Pfeifer ND, Brouwer KL. Sandwich-cultured hepatocytes: an in vitro model to evaluate hepatobiliary transporter-based drug interactions and hepatotoxicity. Drug metabolism reviews. 2010; 42:446-471.

3. Guguen-Guillouzo C, Guillouzo A. General review on in vitro hepatocyte models and their applications. Methods in molecular biology. 2010; 640:1-40.

4. Gomez-Lechon MJ, Castell JV, Donato MT. An update on metabolism studies using human hepatocytes in primary culture. Expert opinion on drug metabolism \& toxicology. 2008; 4:837-854.

5. Nishikawa M, Kojima N, Komori K, Yamamoto T, Fujii T, Sakai Y. Enhanced maintenance and functions of rat hepatocytes induced by combination of on-site oxygenation and coculture with fibroblasts. Journal of biotechnology. 2008; 133:253-260.

6. Busse B, Gerlach JC. Bioreactors for hybrid liver support: historical aspects and novel designs. Annals of the New York Academy of Sciences. 1999; 875:326-339.

7. Solt DB, Medline A, Farber E. Rapid emergence of carcinogen-induced hyperplastic lesions in a new model for the sequential analysis of liver carcinogenesis. The American journal of pathology. 1977; 88:595-618.

8. Moll R, Franke WW, Schiller DL, Geiger B, Krepler R. The catalog of human cytokeratins: patterns of expression in normal epithelia, tumors and cultured cells. Cell. 1982; $31: 11-24$

9. Strnad P, Stumptner C, Zatloukal K, Denk H. Intermediate filament cytoskeleton of the liver in health and disease. Histochemistry and cell biology. 2008; 129:735-749.

10. Andersen JB, Loi R, Perra A, Factor VM, LeddaColumbano GM, Columbano A, Thorgeirsson SS. Progenitor-derived hepatocellular carcinoma model in the rat. Hepatology. 2010; 51:1401-1409.

11. Govaere O, Komuta M, Berkers J, Spee B, Janssen C, de Luca F, Katoonizadeh A, Wouters J, van Kempen LC, Durnez A, Verslype C, De Kock J, Rogiers V, van Grunsven LA, Topal B, Pirenne J, et al. Keratin 19: a key role player in the invasion of human hepatocellular carcinomas. Gut. 2014; 63:674-685.

12. Vuoriluoto K, Haugen H, Kiviluoto S, Mpindi JP, Nevo J, Gjerdrum C, Tiron C, Lorens JB, Ivaska J. Vimentin regulates EMT induction by Slug and oncogenic $\mathrm{H}$-Ras and migration by governing Axl expression in breast cancer. Oncogene. 2011; 30:1436-1448.

13. Kisseleva T, Uchinami H, Feirt N, Quintana-Bustamante O, Segovia JC, Schwabe RF, Brenner DA. Bone marrowderived fibrocytes participate in pathogenesis of liver fibrosis. Journal of hepatology. 2006; 45:429-438. 
14. De Palma M, Venneri MA, Galli R, Sergi Sergi L, Politi LS, Sampaolesi M, Naldini L. Tie2 identifies a hematopoietic lineage of proangiogenic monocytes required for tumor vessel formation and a mesenchymal population of pericyte progenitors. Cancer cell. 2005; 8:211-226.

15. Tang Y, Harrington A, Yang X, Friesel RE, Liaw L. The contribution of the Tie2+ lineage to primitive and definitive hematopoietic cells. Genesis. 2010; 48:563-567.

16. Vigna E, Amendola M, Benedicenti F, Simmons AD, Follenzi A, Naldini L. Efficient Tet-dependent expression of human factor IX in vivo by a new self-regulating lentiviral vector. Molecular therapy. 2005; 11:763-775.

17. Ji J, Wang XW. Clinical implications of cancer stem cell biology in hepatocellular carcinoma. Seminars in oncology. 2012; 39:461-472.

18. Yamashita T, Ji J, Budhu A, Forgues M, Yang W, Wang HY, Jia H, Ye Q, Qin LX, Wauthier E, Reid LM, Minato H, Honda M, Kaneko S, Tang ZY, Wang XW. EpCAMpositive hepatocellular carcinoma cells are tumor-initiating cells with stem/progenitor cell features. Gastroenterology. 2009; 136:1012-1024.

19. Yang W, Wang C, Lin Y, Liu Q, Yu LX, Tang L, Yan HX, Fu J, Chen Y, Zhang HL, Tang L, Zheng LY, He YQ, Li YQ, Wu FQ, Zou SS, et al. OV6(+) tumor-initiating cells contribute to tumor progression and invasion in human hepatocellular carcinoma. Journal of hepatology. 2012; 57:613-620.

20. Yang ZF, Ho DW, Ng MN, Lau CK, Yu WC, Ngai P, Chu PW, Lam CT, Poon RT, Fan ST. Significance of CD90+ cancer stem cells in human liver cancer. Cancer cell. 2008; 13:153-166.

21. Lee TK, Castilho A, Cheung VC, Tang KH, Ma S, Ng IO. $\mathrm{CD} 24(+)$ liver tumor-initiating cells drive self-renewal and tumor initiation through STAT3-mediated NANOG regulation. Cell stem cell. 2011; 9:50-63.

22. Jaramillo MC, Zhang DD. The emerging role of the Nrf2Keap1 signaling pathway in cancer. Genes \& development. 2013; 27:2179-2191.

23. Kobayashi A, Kang MI, Okawa H, Ohtsuji M, Zenke Y, Chiba T, Igarashi K, Yamamoto M. Oxidative stress sensor Keap1 functions as an adaptor for Cul3-based E3 ligase to regulate proteasomal degradation of $\mathrm{Nrf} 2$. Molecular and cellular biology. 2004; 24:7130-7139.

24. Petrelli A, Perra A, Cora D, Sulas P, Menegon S, Manca C, Migliore C, Kowalik MA, Ledda-Columbano GM, Giordano S, Columbano A. MicroRNA/gene profiling unveils early molecular changes and nuclear factor erythroid related factor 2 (NRF2) activation in a rat model recapitulating human hepatocellular carcinoma (HCC). Hepatology. 2014; 59:228-241.

25. Zavattari P, Perra A, Menegon S, Kowalik MA, Petrelli A, Angioni MM, Follenzi A, Quagliata L, Ledda-Columbano
GM, Terracciano L, Giordano S, Columbano A. Nrf2, but not beta-catenin, mutation represents an early event in rat hepatocarcinogenesis. Hepatology. 2015; 62:851-862.

26. Dong Q, Zhu X, Dai C, Zhang X, Gao X, Wei J, Sheng Y, Zheng Y, Yu J, Xie L, Qin Y, Qiao P, Zhou C, et al. Osteopontin promotes epithelial-mesenchymal transition of hepatocellular carcinoma through regulating vimentin. Oncotarget. 2016; 7:12997-3012. doi: 10.18632/ oncotarget.7016.

27. Zhai X, Zhu H, Wang W, Zhang S, Zhang Y, Mao G. Abnormal expression of EMT-related proteins, S100A4, vimentin and E-cadherin, is correlated with clinicopathological features and prognosis in HCC. Medical oncology. 2014; 31:970.

28. Kawai T, Yasuchika K, Ishii T, Katayama H, Yoshitoshi EY, Ogiso S, Kita S, Yasuda K, Fukumitsu K, Mizumoto M, Hatano E, Uemoto S. Keratin 19, a Cancer Stem Cell Marker in Human Hepatocellular Carcinoma. Clinical cancer research. 2015; 21:3081-3091.

29. Dennis JE, Esterly K, Awadallah A, Parrish CR, Poynter GM, Goltry KL. Clinical-scale expansion of a mixed population of bone-marrow-derived stem and progenitor cells for potential use in bone-tissue regeneration. Stem cells. 2007; 25:2575-2582.

30. Herrera MB, Bruno S, Buttiglieri S, Tetta C, Gatti S, Deregibus MC, Bussolati B, Camussi G. Isolation and characterization of a stem cell population from adult human liver. Stem cells. 2006; 24:2840-2850.

31. Lazaro CA, Croager EJ, Mitchell C, Campbell JS, Yu C, Foraker J, Rhim JA, Yeoh GC, Fausto N. Establishment, characterization, and long-term maintenance of cultures of human fetal hepatocytes. Hepatology. 2003; 38:1095-1106.

32. Kristiansen G, Denkert C, Schluns K, Dahl E, Pilarsky C, Hauptmann S. CD24 is expressed in ovarian cancer and is a new independent prognostic marker of patient survival. The American journal of pathology. 2002; 161:1215-1221.

33. Kristiansen G, Winzer KJ, Mayordomo E, Bellach J, Schluns K, Denkert C, Dahl E, Pilarsky C, Altevogt P, Guski H, Dietel M. CD24 expression is a new prognostic marker in breast cancer. Clinical cancer research. 2003; 9:4906-4913.

34. Yamashita T, Honda M, Nakamoto Y, Baba M, Nio K, Hara Y, Zeng SS, Hayashi T, Kondo M, Takatori H, Yamashita T, Mizukoshi E, Ikeda H, Zen Y, Takamura H, Wang XW, et al. Discrete nature of EpCAM+ and CD90+ cancer stem cells in human hepatocellular carcinoma. Hepatology. 2013; 57:1484-1497.

35. Follenzi A, Benten D, Novikoff P, Faulkner L, Raut S, Gupta S. Transplanted endothelial cells repopulate the liver endothelium and correct the phenotype of hemophilia A mice. The Journal of clinical investigation. 2008; 118:935-945. 